Population Study

Poster

Abstract ID: 98

\title{
Traditional postpartum dietary practices and maternal nutritional status
}

\author{
Nor Azwani Mohd Shukri ${ }^{\mathrm{a}}$ Siti Munirah Abdul Basir ${ }^{\mathrm{b}}$ \\ ${ }^{a}$ Department of Nutrition Sciences, Kulliyyah of Allied Health Sciences, International Islamic \\ University Malaysia
}

${ }^{b}$ Traditional Postpartum Dietary Practices and Maternal Nutritional Status

Introduction: In Malaysia, new mothers commonly practice traditional postpartum dietary restrictions, which generally involve food proscriptions and prescriptions. These practices may affect the success of breastfeeding as it may impact the ability to meet the increased nutritional requirements during lactation period. This review examines the postpartum dietary practices of different cultures. It also intends to assess maternal nutritional status during the confinement period. Methods: A literature search was conducted through Mendeley software and PubMed (from year 2001 to 2016) by the keywords postpartum, practices, dietary, beliefs, culture, and nutritional status. Search by bibliography was also done. Results: A total of 30 literatures were examined in this review, which included quantitative and qualitative studies. Typically, mothers in Eastern cultures avoid intake of particular foods perceived to have properties of "cold", "gassy", “itchy”, etc. A study found that women in confinement have 19\% lower mean energy intake as compared to Malaysian Recommended Nutrients Intake (RNI) and more than $90 \%$ of mothers did not meet nutritional requirements for some micronutrients and minerals. As lactating mother needs higher energy and nutrients intake, food restrictions practiced during this period may impact their ability to meet these nutritional requirements. Consequently, the lactation process may be affected. Conclusions: More investigations are needed to determine the potential effects of dietary postnatal restrictions on maternal nutritional status and lactation practices. This is necessary to optimize the effectiveness of breastfeeding, which would enhance the intermediate as well as the future health of the country's next generations.

KEYWORDS: postpartum, dietary, nutritional, status 